\title{
Unfolding Tragedy in Ukraine
}

\author{
Twigg J \\ Department of Political Science, Virginia Commonwealth University, USA
}

*Corresponding author: Twigg J, Department of Political Science, Virginia Commonwealth University, USA, E-mail: jtwigg@vcu.edu

Citation: Twigg J (2015) Unfolding Tragedy in Ukraine. J Aids Hiv Infec 1(1): 102. doi: 10.15744/2454499X.1.102

Received Date: March 02, 2015 Accepted Date: March 27, 2015 Published Date: April 07, 2015

In bold contrast with most other countries in the Eurasian region, Ukraine legalized opioid substitution therapy (OST) for injection drug users in 2004. OST provides addicts with drugs that safely substitute for heroin and ease dependence, all under the supervision of trained support staff. With HIV prevalence estimated around 20\% among the country's 250,000 active opiate users, and needle sharing and other unsafe injection practices unquestionably the leading mode of HIV transmission in the region, this policy shift was rightly seen as a crucial step forward in Ukraine's fight against HIV/AIDS. Although coverage remains spotty and inadequate, the number of Ukrainians on substitution therapy increased to around 2500 in early 2009 and then to over 8,300 receiving treatment in 140 facilities by early 2014.

Russia is quite another story. Despite continued persuasive efforts from the United Nations Office on Drugs and Crime and other agencies, Russia remains staunchly opposed to the legalization of methadone and buprenorphine. Its arguments - all of which run counter to internationally recognized research and experience - center around the likelihood of development of a black market for opioid substitutes, and the unacceptability in principle of "replacing one addiction with another". The Russian government also refuses to fund needle exchange programs, and local police regularly harass harm reduction buses run by non-governmental organizations. Russia's drug users are therefore forced to rely primarily on the only officially sanctioned treatment: cold-turkey withdrawal.

The availability of opioid substitution has produced tangible benefits in Ukraine. After years of steady increase, new HIV infections there fell from 21,777 in 2011 to 20,743 in 2012, with stabilization of the epidemic particularly apparent among those who inject drugs (in Russia, incidence rose 13\% over the same time period). One study in Ukraine found a $90 \%$ reduction in opiate use and a $20 \%$ decline in sexual risk among heroin addicts after starting methadone treatment, with $94 \%$ treatment retention after 20 weeks. Another indicated that integration of methadone maintenance with tuberculosis treatment - in an environment where HIV/ TB co-infection is a growing challenge - significantly improved retention in TB treatment and TB medication adherence among people who inject drugs $[1,2]$.

Russia's annexation of Crimea one year ago has ground these gains to a halt there. According to a 2012 UNICEF survey, about 12,000 of Crimea's two million inhabitants are HIV positive. Prior to the conflict with Russia, 805 Crimean drug addicts - about 200 of whom were infected with HIV - were taking methadone or other OSTs. Initially, the Russian authorities promised a phased approach to the integration of Ukrainian and Russian law in cases where the two collided, opening the possibility of at least a reasonable weaning period for OST patients. But a sudden change of course appeared in March 2014, when the Crimean OST program was abruptly banned.

Doctors prescribing methadone after that time were threatened with prison. Russian anti-drug authorities gleefully implemented a widely televised burning of tens of thousands of methadone doses reportedly collected from Crimean clinics, alleging that black-market sales were fueling organized crime. The head of the Russian Federal Drug Control Service has claimed (against all evidence) that OST has led to a death rate among Ukrainian drug users twice that in Russia, and even went so far as to blame methadone for the entire security crisis in Ukraine, saying that "methadone addicts" were lured by "cultists" to "serve as cannon fodder on the Maidan [Kiev's Independence Square, where the initial large anti-government protests were held] and later in southeastern Ukraine."

By the end of January of this year, according to UN Special Envoy for AIDS Michel Kazatchkine, between 80 and 100 of those 805 Crimean OST patients had already died, primarily from suicide and overdose. Several NGOs have financed travel costs for patients to relocate to other parts of Ukraine to continue treatment. But many of these people are also suffering from other diseases besides HIV, including hepatitis $\mathrm{C}$ and $\mathrm{TB}$, and find the prospect of uprooting their lives unthinkable. Too many have already returned to their former heroin addictions.

The problem is now spreading beyond Crimea, with the Ukrainian government refusing to send not only OSTs but also antiretroviral drugs to its Eastern regions under the control of Russia-backed rebels as part of an overall blockade. The Britishbased International HIV/AIDS Alliance in Ukraine reports that more than 300 OST patients in the disputed Lugansk and Donetsk regions have lost access to treatment as a result of this decision, with over 500 more in "imminent" danger of exhausting remaining supplies. 
Last week, the Global Fund announced new grant agreements totaling US\$ 134 million to fund Ukrainian efforts against HIV and TB, with particular focus on people who inject drugs (among other risk groups). But politics threatens to over whelm these efforts. The government in Kiev should make a humanitarian exception to its blockade of the Russian separatist-controlled regions in the East, allowing a safe corridor for methadone and buprenorphine, clean syringes, HIV test kits, and condoms. And the international community must redouble its efforts to convince Russia to rethink its policy on OST, at least in Crimea. Failure here will magnify the tragedy of an already catastrophic situation.

\section{References}

1. Dvoriak S, Woody G, Schumacher J, Pecoraroi A (2012) Methadone Maintenance and HIV Risk in Ukraine. NIDA Abstract Database.

2. Morozov O, Dvoriak S, Altice FL (2013) Methadone Treatment Improves Tuberculosis Treatment among Hospitalized Opioid Dependent Patients in Ukraine. Int J Drug Policy 24: e91-8.

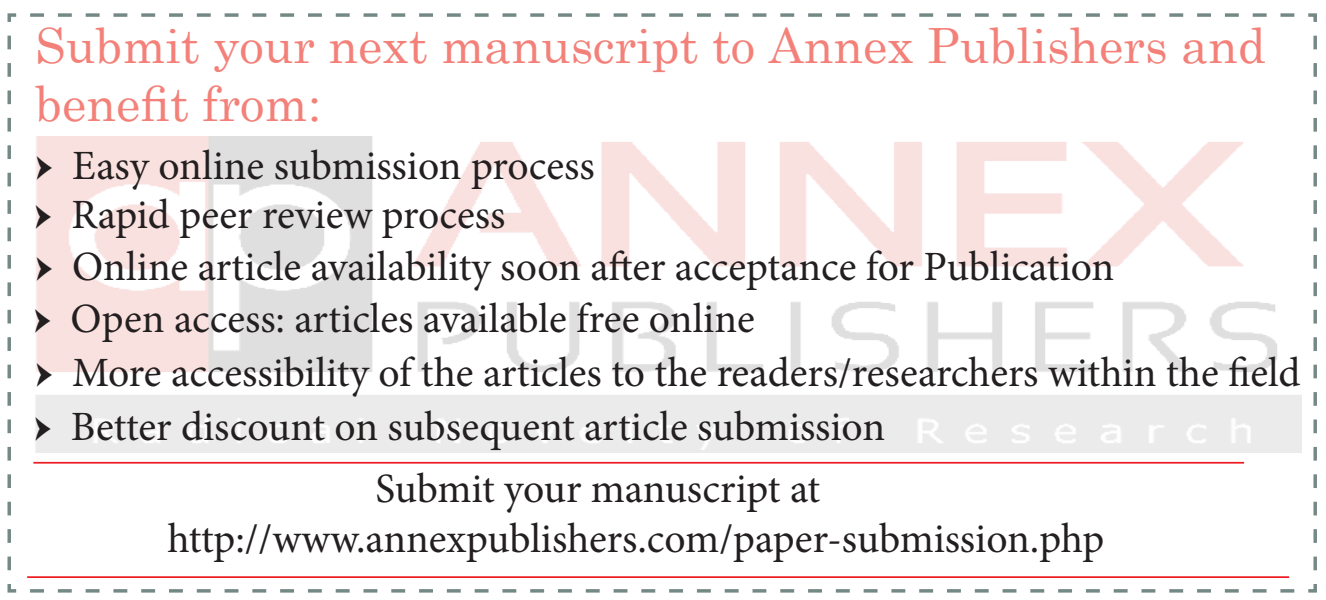

